\title{
SYSTEMIC THERAPY OF HYPERACTIVE CHILD: A CASE STUDY
}

\section{Hristo Kyuchukov, Michel Ackerman}

\begin{abstract}
The paper presents a study with a case study with a nine-year-old German boy with ADHD. The child was tested with the "Test of Everyday attention for Children. Deutsche Adaptation. 3" (2006). The test measures the time of the performing of the test in seconds and the number of the errors the child does. Our general observation on the child by the performance of the test is that the child gets easily tired and after working on 5-6 pages of the Test he loses concentration. Based on the research the systemic therapy with the child is presented and the Reframing as a method was used.
\end{abstract}

\section{Keywords}

ADHD, systemic therapy, diagnoses, reframing

\section{Introduction}

Our motivation to work on this particular topic comes from our work as Child and Youth Therapist in Berlin, Germany. Our work with children from different nationalities and cultures who had the diagnoses of ADHD from very early age actually made us interested to investigate this issue much deeper. We simply wanted to be helpful to the children and their families to find the best way to deal with the hyperactivity in their everyday life. One important thing what we understood in our work of therapist with hyperactive children is that very often the hyperactivity goes together also with some other sicknesses, which makes it very difficult for treatment and therapy.

The goal of this study is to bring a new knowledge in the field of systemic therapy with hyperactive children. For this purpose we did observed a nine-year-old German boy who is living with his mother and attends a primary school in Berlin. Our observations on the child were systematic and enough long time (almost six months) and although 
the observations are only with one child we think the findings and conclusions can be applicable to other cases of hyperactive children as well.

The objectives of the study are the following:

1. To make a research with an ADHD child regarding his attention deficits.

2. To bring some conclusions in the relation with the systemic therapy, how to organize it in order to be helpful to the child and to the family.

\section{Definitions}

Attention-Deficit/Hyperactivity Disorder (ADHD) has been a subject of intensive research for decades (Barkley, 2006). According to the American Psychiatric Association (2000) it is a childhood disorder that affects many aspects of human being, particularly young children. Although the studies on ADHD last decades or so produced number of publications, still the interest to this problem and continues.

Although research on family of children with ADHD continue to be acknowledged, (e.g., Sonuga-Barke, Auerback, Campbell, Daley \& Thompson, 2005; Kolaříková, 2014), the debates about children diagnosed of ADHD, particularly, its occurrence and origin continues to range on. More disturbing is the fact that developmental conceptualizations of the syndrome in children and adolescence have been neglected. This made it hard for practitioners and families of children diagnosed with ADHD to cope with its challenges, and projected the problems and discriminations experienced by families and children with ADHD an important issue for consideration.

ADHD is multidimensional disorder that exacts a significant effect on individual and society. This disorder has negative impact on families. As the most generally diagnosed neurobehavioral illness in children, the disorder is mostly treated with stimulant and nonstimulant drugs (United States, 2003, \& 2007; Pastor, \& Reuben, 2008). Even though the exact causes of the ADHD are still unknown, past and present research confirmed the significant effect of genetic and environmental factors on the disorder (Nigg, Nikolas, \& Burt, 2010; Thapar, Langley, \& Asherson, 2007). Besides, research on ADHD emphasized more on the period of birth by establishing a strong correlation between period of birth and children psychological and behavioral disorders. This is in contrast with several other disorders where a reliable seasonal form is yet to be established. (Atladóttir, Parner, \& Schendel, 2007; Hauschild, Mouridsen, \& Nielsen, 2005; Kaleja, 2013).

As an unsatisfactory umbrella term, ADHD is applied to children with broadly differing temperaments and functional problems in school, home, and social settings. This group of children shared certain core features, such as limited sustained attention span, poor impulse control, and motor over activity. They also developed abnormal syndromes, such as severe development, distraction and thoughtlessness that cause severe impairment in their learning. Research on ADHD also showed a strong genetic orientation on the disorder. For example, the inattentiveness aspect of the disorder is documented as 
fantasizing, distractibility, and associated with problems, such as lack of concentration on specific task for a lengthy period.

Research in the last sixty years has witnessed the use of several terminologies for attention deficit- hype reactivity disorder (ADHD). Some of this terminology includes: hyperkinetic impulse disorder, minimal brain dysfunction, hyperactivity, attention deficit disorder. However, the core characteristics of the disorder are inattention, impulsivity, and hyperactivity and affects about $4 \%$ of all children. Besides, the signs of the syndrome are more noticeable in young people and vary between 3 to $11 \%$ or more (Berger, 2011; Childress \& Berry, 2012). However, despite its occurrence in young children, the origin of the disorder is yet to be identified. This difference in expression revealed the diverse conceptions of the primary symptoms and its assumed fundamental pathophysiology.

\section{Methodology of the Study}

\section{The Child}

Object of this study is S. - the nine-year-old boy, born in Berlin, who came to us with his mother for therapy. The information about the child we got from the mother during our first meeting. The following characteristic of the child is based on the information given by the mother.

S. was diagnosed with ADHD when he was in the kindergarten. The diagnoses and the behavior of the child put him in a situation that he had to change constantly the kindergartens and later also primary schools.

The child was born in Berlin and he lives here since he is born. S. lives with his mother. The father left the mother in the first week when the child was born. The mother is a freelancer - makeup artist.

S. is the first and only child for the mother. At the beginning a female friend was helping the mother to raise up the child. The parents of the mother who live in South Germany moved to Berlin to help her also with raising up the child. After a year they moved back to South Germany, because the mother had the feeling that her parents are getting too much attached to the child and she did not like it. This brought some conflicts between them and they left Berlin

The mother was never married. She is the basic caregiver of the child. There is no any other adult who is taking care of $\mathrm{S}$. The strong sides of the child are the abilities to work manually and to work with his body. The weak sides of S. are the lack of self-control and lack of concentration. The child has night bed-wetting and he does not take medicine against it. The child was born with kind of infection. The reason for the infection was that the child got from the fluid when he still was in the womb of the mother. The current health situation of the child is good. He does not take any medicine.

S. had participated in intervention program. He has learning difficulties and particularly Dyslexia problems. Sometime he is aggressive and he has problems with self-regulations. S. does not have intellectual disability and he is not drug addicted. 
He changed two kindergartens and two schools. He has problems with the adaptability. In primary school the child has a lot of problems. S. has poor concentration, difficulties with completing task and difficulties following instructions. Sometimes he shows aggressiveness towards adults and children.

S. does not get depressed. He is very sensitive. He does not have low self-esteem. He does not have difficulties in making decisions: if he is interested in something he makes it.

In the mornings the child has problems sometimes getting ready for school. He has also problems playing with other children. He does not have friends and he does not have a normal communication with children form the class. He is very motoric active at home, and he also helps the mother. He goes very late to bed ad during the night the child does not sleep well.

Outside of school the child does not have any contacts with other children. He likes the school where he is now, but the child cannot read and write although he is in the $3^{\text {rd }}$ grade.

\section{Testing of the child}

The child was tested with a standardized test TEA-Ch Test of Everyday attention for Children - Deutsche Adaptation (2006). The test has two forms: Form A and Form and both of them were used for the testing. The test itself is a picture test (see examples from the Tests in Appendix). The test measures the time of the performing of the test in seconds and the number of the errors the child does. The child was examined about his attention- how long he can count the forth and back without errors and the number of errors were measured.

The test was necessary to prove that diagnoses done by the medical investigations are correct.

\section{Results from Testing}

Before the real tests the child had a pretesting, where the child had the task to find the same pair figures among many other figures. In the pretesting the child showed very good results. He found all the same pairs with just one or two mistakes. The pretesting showed that the child's concentration is good and he can find the pairs of figures. Here I will present the results from the two testing with Form A and Form B.

\section{Testing with Sub-Test A: Form A}

Before to start the real testing there were two exercises. The results from the exercises will not be taken into account.

The task of the child is to count the number of figures given in a page forth and back. The changes is done after arrow appearance (see the Appendix). For example the child starts to count: one, two, three, four, five... and then an arrow appears and its direction is down. 
That means the child continues to count the next figures in a straight line as they are, for example one, two, three... If the arrow appears to be with direction up, than the child has to count the figures in a reverse order, for example: four, three, two, one.

There are seven batteries in Sub-Test A. The next table 1 presents the number of the errors, the time of the performance of each battery from the Sub-Test and the number of the changes of the arrow in the battery. The changes of the arrow are given in the test and they are constant.

Table 1. Results from the first Testing with Form A

\begin{tabular}{|l|r|r|r|r|r|r|r|}
\hline Batteries & 1 & 2 & 3 & 4 & 5 & 6 & 7 \\
\hline Errors in counting & 0 & 1 & 2 & 2 & 2 & 1 & 2 \\
\hline Seconds & 15 & 15 & 18 & 28 & 32 & 18 & 33 \\
\hline N of changes of arrow & 3 & 2 & 3 & 4 & 5 & 3 & 6 \\
\hline
\end{tabular}

As can be seen from Table 1 with the increase of the number of the changes of the arrow the time needed for the performance of the battery is increasing. By three changes of the arrow the child performs the battery respectively for fifteen seconds (battery 1), for eighteen seconds (battery 3 and 6 ) and by six changes of the arrow (battery 7 ) the child needs almost a double time for the performance of the battery - thirty-three seconds. Let see how the child performs the second Sub-Test B.

\section{Testing with Sub-Test B: Form B}

The second testing was done with Sub-Test B and Form B. The child has the same task as it is by Sub-Test A counting forth and back, changing the counting by the change of the arrow. The results from the second testing is presented at the next Table 2.

Table 2. Results from the first Testing with Form B

\begin{tabular}{|l|r|r|r|r|r|r|r|}
\hline Batteries & 1 & 2 & 3 & 4 & 5 & 6 & 7 \\
\hline Errors in counting & 1 & 0 & 0 & 3 & 3 & 1 & 1 \\
\hline Seconds & 26 & 8 & 16 & 26 & 28 & 22 & 27 \\
\hline N of changes of arrow & 4 & 2 & 3 & 3 & 4 & 3 & 5 \\
\hline
\end{tabular}

The Table 2 shows that the child is familiar with the task and he has performed two batteries without any errors - battery 2 and 3 . The time for the performance of battery 2 with 
two changes of the arrow is eight seconds and the time for the performance of battery 3 with three changes of the arrow is sixteen seconds. However, it is interesting that for the performance of battery 3 and 4 with the same number of changes of the arrow -3 , the child needs different time for performance of the battery (sixteen seconds performing battery 3 and twenty-six secs performing battery 4). It is interesting that he also have different numbers of errors in the performance of these two batteries: zero errors by battery 3 and three errors by battery 4 . Battery 6, which is also with three changes of the arrow, is performed for twenty-two secs. and has one error.

Comparing Table 1 and Table 2 one can see some similar tendencies in the performance of the batteries. The batteries with the same number of changes of the arrows, have more or less the same time for the performance: battery 4 from Table 1, battery 1 and battery 5 from Table 2 are performed respectively for twenty-eight secs, twenty-six secs, and twenty-eight secs. The timing is good but the number of the errors is more important: they vary from one to three as the highest number of errors three for twenty-eight secs is done by battery 5 in Table 2, which shows that concentration of the child on the performance of the battery is getting low.

It is interesting also the performance of the batteries with four changes of the arrows. In both tables the results by performing these batteries are different: battery 4 in table 1 is performed for twenty-eight secs and the child has two errors, battery 1 in Table 1 is performed for twenty-six secs with one error and battery 5 from the same table is performed for twenty-eight secs with three errors. Again is observed the same tendency as by the performance of the batteries with three changes of the arrow: with the increase of the batteries the concentration of the child is getting low and he makes more errors. Our general observation on the child by the performance of the test is that the child gets easily tired and after working on 5-6 pages of the test he loses concentration. We had to remind him that he still have few pages to go through in order to complete the tasks.

\section{Interview with the teachers of the child}

In order to get a better picture of the child's ability of concentration and the child's cognitive development we met with the teacher of the class and we had an interview with her. We also had the possibility to observe the child in the school acting with other children during school activities.

According to the teacher, at the beginning after the arrival of the child to the school he did not have any contacts with the adults (teachers) in the school. He was not having contacts with the children either. The school had one week "Green school" where S. took place as well and after that he started to be more open to the teachers. But he has just one favorite teacher - the teacher of the class, with whom we had the interview. According to the teacher the child does not have so much interest to the educational process. Still by the age of nine he cannot read and write in German. He like mathematics, but also has difficulties in counting and solving mathematical tasks. 
His social contacts with other children form the class are also very limited. At the begging he did not communicate with other children and he did not have any friends but lately he developed a friendship with one boy who. For the time being the communication of the child is limited to the teacher of the class and that one boy form the class.

S. does not show interest in the educational process. Sometimes he likes to take part in some art activities, but again he is not so much involved. He loves to paint and to do sport but he does not like so much other activities which the class does.

In our therapy work with the child in order to make him interested towards the education and reading and writing I both him some children's books and books for writing and during the therapy sessions some time we used to read some 5-10 min. books. These session showed to me that the child does not know the alphabet and he can hardly read or write in German. Mainly I was the one who was reading to him and asking him questions regarding the content of the texts.

From the conversations with the mother of the child we understood that they do not have children books at home and she does not read any books to him. She believes that he will learn to read and write by himself when he grows up and she should not put him in a stress asking him to learn the alphabet or to learn to count and solve mathematical tasks.

\section{Reframing}

\section{Definitions of reframing}

The classical definition of reframing comes from Watzlawick et.al (1974):

"The reframe, than, means to change the conceptual and /or emotional setting or viewpoint in relation to which the situation is experienced and to place it in another frame which fits the 'facts' of the same concrete situation equally well or even better, and thereby changes its entire meaning." (Watzlawick et al., 1974, p. 95)

Watzlawick et al. (1974) also give additional descriptions of reframing. The first one of these descriptions emphasized the central role that the categorization plays in the process of reframing:

"In its most abstract terms, reframing means changing the emphasis from one class membership of an object to another, equally valid class membership or especially, introducing such a new class membership into the conceptualization concerned." (Watzlawick et al., 1974, p.98)

Secondly, the reframing resembled psychological interpretation, but had different goals. Reframing has been used in a variety of ways in psychotherapeutic conversations. First, it can be used to define the problem situation in new ways, usually in such a way that the problem will be easier to solved. 
Secondly, it can be used in reduction or intensification of clients' emotionality in order to produce mobilization toward the goal. Thirdly, with the help of reframing the client can be motivated to do the therapeutic tasks that are suggested in therapy. Fourthly, with the help of reframing the client's motivation for therapy can be relabeled: "only strong people can admit problems and weaknesses" and have courage to seek help.

\section{Reframing in therapy with the mother}

The most important use of reframing is, however as a part of the therapeutic conversation itself. The therapist suggests through questions, comments are descriptions, etc., alternative ways to see and talk about client's situation.

\section{Situation 1}

During one of the first meetings the mother of S. reported he has bedwetting during the night.

Therapist (T): Since when S. had the bedwetting?

Mother(M): Since his childhood.

T: Did you bring him for medical checking, to understand what the reason is for that. M: No, because S. does not like to be checked. Once my Father brought him to a doctor but the doctor wanted to check him and S. did not like it and then they left without any checking.

T: Yes, this is very good that you respect the child's opinion, but don't you think that he soon will enter puberty and then maybe he will be shy to meet girls, because he will be stinking form the bedwetting. During the puberty he will get interested in girls and he will meet girls....

M: Yes you are right....but he does not like doctors and he does not like to be checked...

T: Why don't you try to speak to him again and to explain to him why it is important to be checked by the doctor, maybe you will convince him.

As a result of this therapy the mother promised to bring the child to a doctor if we find a specialist in child urology. I did find such a specialist and made an appointment for the child and then the mother brought S. for control checking and treatment.

The mother did not know how to behave with the child. She was telling me that when the child was younger, he was much more active: running around, jumping, destroying almost everything, and the mothers of other children from the kindergarten stopped to communicate with her and no one invited them to birthday parties or to any other celebrations. However, lately the mother observed some changes in his behavior: he is getting very isolated from other children - not so active, but rather opposite. He preferred to stay alone, and play alone and not to be so much communicative.

In one of the therapy sessions with the mother we understood that the child has an interest towards painting and playing with clay, but at home she does not have anything to give him in order to support his artistic interest. 


\section{Situation 2}

T: Do you have possibility to buy him any materials for painting

M: no, I cannot afford it. I am freelancer and do not earn much. I think this will be also a waste of money....

T: but how do u feel about his artistic interest towards painting...

M: I do not see any use of it...

T: don't you think that this could be somehow helpful for his development...

M: I do not know...

T: why don't you bring him to kind of children's center after school where he can paint and meet other children...that can help him to develop his abilities...

M: I do not know what to do....

T: If you wish I can search for such a center and register him there...

\section{Reframing in the therapy with S.}

During the therapy with the mother we understood that $\mathrm{S}$. cannot read and write. The opinion of the mother is that he somehow will learn it by himself and there is no need to press him. In our therapy sessions with S. we started to read children's books in order to motivate him to learn the alphabet.

\section{Situation 3}

T: Did you like the book?

S: yes, it was interesting...

T: what did you like most?

S: the dinosaurs...

T: can you read the word dinosaurs

S: no

T: is there the letter $S$-your letter- in the word dinosaurs, show me....

S: hmmmm.... I do not know

T: do you want to learn it ...

S: yes....

T: are you interested to read books if I give you one.... am sure you can do that

S: yes....

In order to check his attention and cognitive development we played a game with him. S. had the task among puppet animals and birds to group the wild animals/birds and home animals/birds. S. did not like this idea at the beginning:

\section{Situation 4}

T: Look, there are so many puppet animals and birds... do you want us to play with them...

S: no...l am not a child...this is for small children... 
T: yes...but I like some time to play with them...look they are so beautiful...look these birds...

S: yes they are beautiful...

T: do you have animals at home...dog or cat... Which other home animals do you know...can you put them together...

S: these here...horse, sheep...

T: super... do you know some home birds...

At the beginning of the session $\mathrm{S}$. was not so much motivated to do the exercise with me but towards the end of the exercise he showed a good attention to the task and most of the animals and birds were correctly grouped.

In the case of $\mathrm{S}$. the reframing with his mother and with S. himself was successfully used for achievement the goals of the therapy. Together with the reframing also circular questions were used. In my therapy with S. the systemic approach together with technics from play therapy and speech therapy were used.

\section{Conclusions}

The systemic approach treats the client as a part of a system. In the case of S. was treated as a part form Family $\longleftrightarrow$ School system. The diagnoses of the child with ADHD from the kindergarten most probably was for the period of the early childhood development of the client. It is more than obvious that he is developing and changing with growing up. In the primary school the child does not show anymore the symptoms of the hyperactivity. It is exactly opposite - the child shows kind of closed non-communicative attitude to the outside world.

The testing of the child with the Test of attention deficits showed very good results good timing for performance of the test and limited number of errors. This clearly show that the child does not have so much attention deficit. It is clear that something was wrong in the approach towards the child's education form the side of the mother. It is very possible also that the type of school where he studies (Freie Schule) to offer him skills and knowledge how to behave socially. According to the teacher of the class he is not so much interested in the educational process, and he was not very open and communicative to the children, but only after one year in the school he got a friend a younger boy and they are always together in the school.

Due to the therapy the relationship between us as a therapist and the child as a client got better and better. The child trusted us more and more, until the moment he told the first author that he likes him very much because he remind him his grandfather.

As a conclusion we can say that the objectives of the study were fulfilled:

- A research with an ADHD child regarding his attention deficits was made.

- Some useful conclusions to organize the therapy work with ADHD children are made. 
All this gives us the right to make the conclusion that the love and respect towards the client in the therapy plays an important role in changing his behavior. In order to help the client the system should be evaluated as a whole from different angles. The small research we did with the child, the conversations with the mother and the teacher, my visit to school and my observations of the child in the school environment gives me the right to conclude that the child in early ages had the ADHD as a diagnose, but it is more than obvious that it is changed. The child is changed a lot and his development comes to place thanks to the systemic therapy.

\section{References}

American Psychiatric Association (2000). Diagnostic and Statistical Manual of Mental Disorders. $4^{\text {th }}$ ed. Washington, DC: American Psychiatric Association.

American Psychiatric Association. (2013). Diagnostic and Statistical Manual of Mental Disorders. $5^{\text {th }}$ ed. Washington, DC: American Psychiatric Association.

Atladóttir H.O., Parner E.T., \& Schendel D. (2007). Variation in incidence of neurodevelopmental disorders with season of birth. Epidemiology, 18, 240-245.

Barkley, R. A. (2006). Attention deficit/hyperactivity disorder: A handbook for diagnosis and treatment ( $3^{\text {rd }}$ ed.). New York: Guilford.

Berger I. (2011). Diagnosis of attention deficit hyperactivity disorder: much ado about something. Israeli Medical Association Journal, 13, 571-574.

Childress, A.C., \& Berry, S.A. (2012). Pharmacotherapy of attention-deficit hyperactivity disorder in adolescents. Drugs, 72, 309-325.

Hauschild K.M., Mouridsen S.E., \& Nielsen S. (2005). Season of birth in Danish children with language disorder born in the 1958-1976 period. Neuropsychobiology, 51, 93-99.

Kaleja, M. (2013). Etopedická propedeutika ve speciální pedagogice [Etopedia Propedeutics in the field of Special Education]. Ostrava: University of Ostrava.

Kolaříková, M. (2014). Key Factors Supporting or Inhibiting the Process of Identity Acceptance Related to Families with Disabled Children. Journal of Psychology \& Psychotherapy, 4:160.

Nigg J., Nikolas M., \& Burt S. A. (2010). Measured gene-by-environment interaction in relation to attention-deficit/hyperactivity disorder. Journal of the American Academy of Child and Adolescent Psychiatry, 49, 863-73.

Pastor P. N., \& Reuben C.A. (2008). Diagnosed attention deficit hyperactivity disorder and learning disability: United States, 2004-2006. Vital Health Statistics, 10, 1-14. 
Sonuga-Barke, E. J., Auerbach, J., Campbell, S. B., Daley, D., \& Thompson, M. (2005). Preschool varieties of hyperactive and dysregulated behaviour: Multiple pathways between risk and disorder. Developmental Science, 8, 141-150.

Thapar A., Langley K., \& Asherson P. (2007). Gene-environment interplay in attentiondeficit hyperactivity disorder and the importance of a developmental perspective. British Journal of Psychiatry, 190, 1-3.

United States, 2003 and 2007 (2010). Increasing prevalence of parent-reported attentiondeficit/hyperactivity disorder among children, MMWR Morb Mortal Wekly Rep, 59, 1439-43.

Watzlawick, P. et al. (1974) Change: Principles of Problem Formation and Problem Resolution. N.Y.: W.W. Norton.

\section{Authors}

Prof. Dr. hab. Hristo Kyuchukov, PhD. et DrSc Magdeburg-Stendal University of Applied Sciences

Postfach 36 55, 39011 Magdeburg, Germany

hkyuchukov@gmail.com

Michel Ackerman, MA

Berlin, Germany 


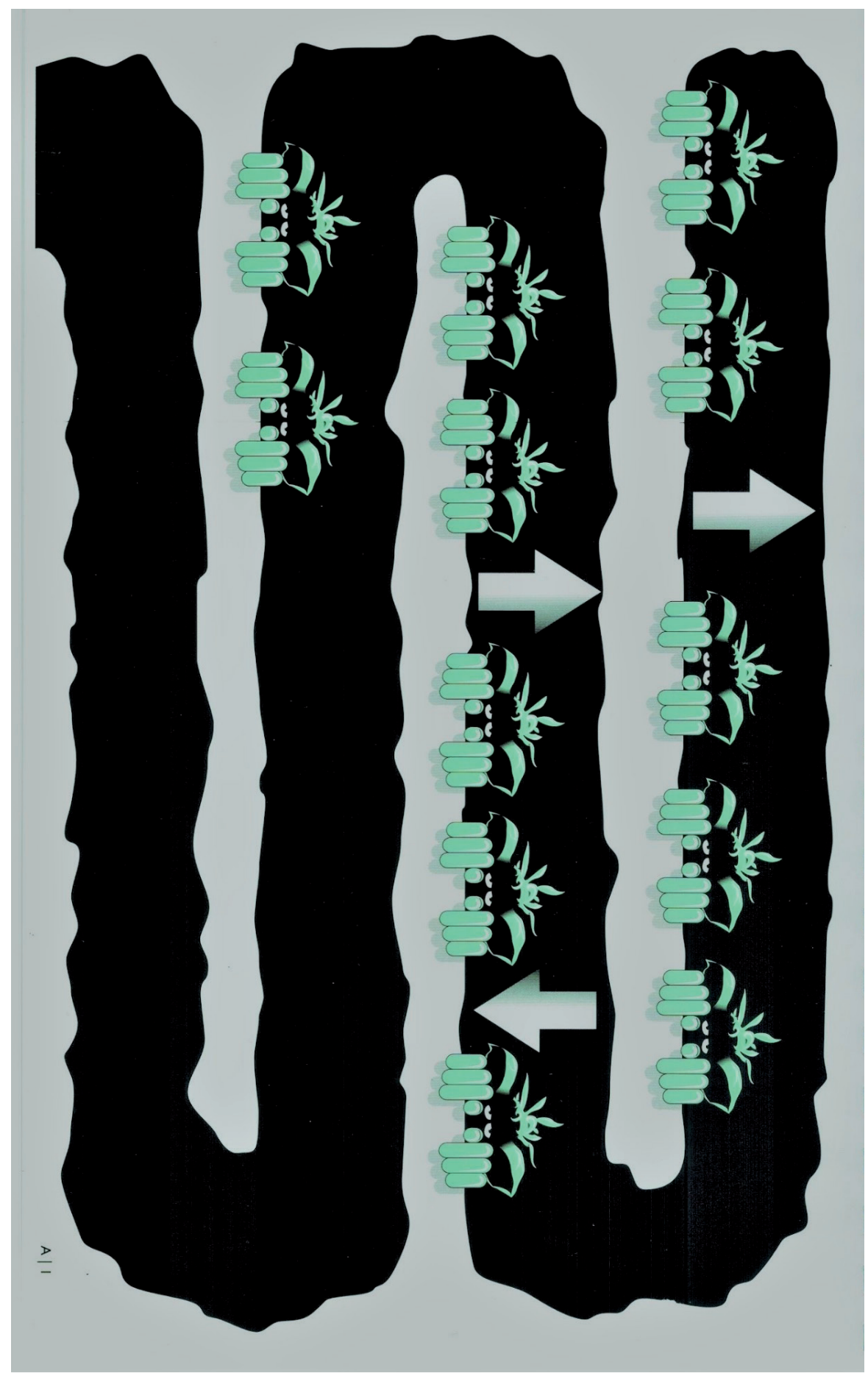




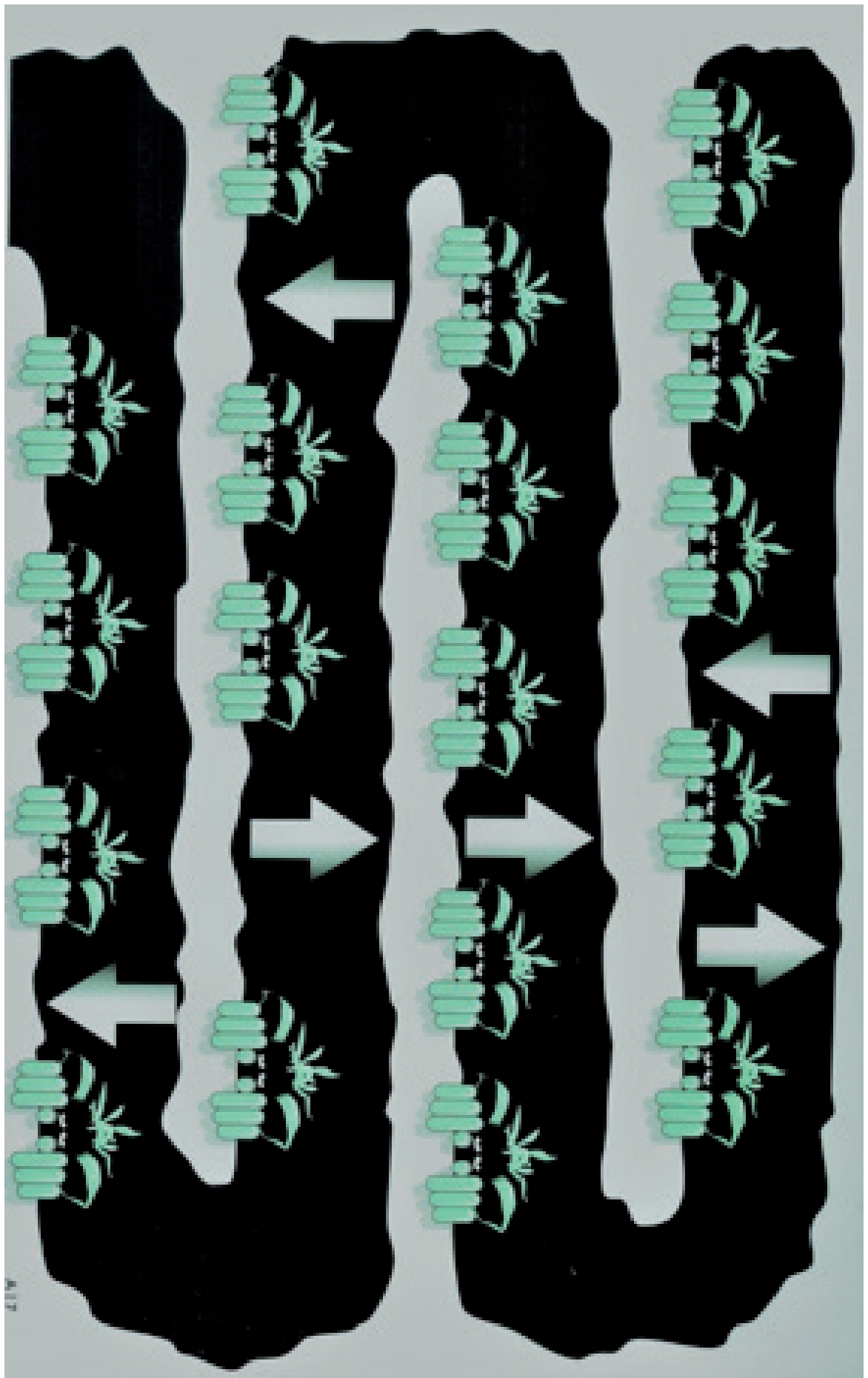

